\title{
Maternal Serum Ischemia Modified Albumin as a Marker of Oxidative Stress in Hypertensive Disorders of Pregnancy
}

Kavitha $S^{1}$, Lavanya $Y^{2}$

\begin{abstract}
Background: Ischemia modified albumin, IMA is albumin which has altered in its amino terminal due to ischemia, following which, it loses its capacity to bind to metal cations like cobalt ions. It is also a candidate marker of oxidative stress. Normal pregnancy is associated with production of free radicals compared to non-pregnant women.

Materials and methods: In this prospective study, the IMA and IMA albumin ratio levels of 40 pregnant women with pregnancy induced hypertension of age group 18-40 years were compared with the 40 age matched healthy pregnant controls. The albumin cobalt-binding test was used to estimate the IMA levels and serum albumin levels were estimated using absorbance by Bromocresol green.

Results: Mean levels of IMA were higher in the case group as compared to control group $(0.52 \pm 0.1 \mathrm{ABSU}$ vs $0.04 \pm 0.03 \mathrm{ABSU}, \mathrm{p}<0.05)$. The albumin levels were lower in the patients' group compared to the controls' group and the difference was statistically significant $(p<0.05)$. The ratio of IMA to normal serum albumin (IMAR) was higher in the patients' group than the controls group $(\mathrm{p}<0.05)$.

Conclusion: Ischemia modified albumin and the ratio of IMA to normal serum albumin are significantly elevated in hypertensive disorders of pregnancy as compared to normal healthy pregnant controls and therefore are useful biomarkers of pregnancy induced hypertension.

Keywords: Biomarker, Ischemia modified albumin, Pregnancy induced hypertension.

Indian Journal of Medical Biochemistry (2019): 10.5005/jp-journals-10054-0102
\end{abstract}

\section{INTRODUCTION}

Ischemia modified albumin (IMA) is albumin which has undergone alterations in its amino terminal end consequent to ischemia, following which; it loses its capacity to bind to metal cations like cobalt ions.' IMA is formed when there is an 'oxidative stress', an imbalance where there is an excess of oxidants and a decreased amount of antioxidants. A number of researches have established the finding that IMA is elevated in acute coronary syndromes and has proved to be a useful adjunct in diagnosing myocardial ischemia. The FDA has recently approved the use of Ischemia Modified Albumin as a biomarker in Myocardial Ischemia. ${ }^{2}$ It is also elevated in other pathological conditions such as Diabetes Mellitus, renal failure, cerebrovascular accidents and disseminated chronic liver disease. However, researches on whether IMA is elevated in Pregnancy Induced Hypertension (PIH; preeclampsia, eclampsia and gestational hypertension) are still underway. Preeclampsia is a pregnancy disorder characterised by hypertension to the extent of $140 / 90 \mathrm{~mm} \mathrm{Hg}$ or more with proteinuria (300 mg of protein or more in a $24 \mathrm{~h}$ urine sample), after the 20th week of gestation in a woman who was previously normotensive and non-proteinuric. It predisposes to eclampsia, which is characterised by convulsions. Preeclampsia can be classified as mild when the blood pressure is less than $160 / 110 \mathrm{~mm} \mathrm{Hg}$ without significant proteinuria and eclampsia when there are one or more of the following manifestations: BP: $\geq 160 / 110 \mathrm{~mm} \mathrm{Hg}$, protein excretion $>5 \mathrm{~g} /$ day, platelet count $<100,000 / \mu \mathrm{l}$, cerebral disturbances, severe epigastric pain, oliguria, elevated liver enzymes, retinal haemorrhages, papilledema and pulmonary oedema.

More number of studies is required to validate whether markers of inflammation and oxidation are significantly elevated in $\mathrm{PIH}$ or
${ }^{1}$ Associate Professor, ${ }^{2}$ Student

${ }^{1}$ Department of Biochemistry, PSGIMSR, Coimbatore, Tamil Nadu, India

${ }^{2}$ Radiology, UCMS and GTB Hospital, Delhi, India

Corresponding Author: Kavitha S, Associate Professor, Department of Biochemistry, PSGIMSR, Coimbatore, Tamil Nadu, India, e-mail: kavie2001@gmail.com

How to cite this article: Kavitha S, Lavanya Y. Maternal Serum Ischemia Modified Albumin as a Marker of Oxidative Stress in Hypertensive Disorders of Pregnancy. Indian J Med Biochem 2019;23(2):270-272.

Source of support: Project done under ICMR-STS

Conflict of interest: None

not. IMA is one such candidate marker of oxidative stress. From among the limited number or studies which have investigated IMA as an oxidative marker in $\mathrm{PIH}$, there is a disparity in the results with a few studies supporting the notion while others refute it. This study will thus be a valuable contribution to the amalgam of researches pertaining to this topic. Further the study also aims at studying the association of IMA levels with the different types of hypertensive pregnancies (gestational hypertension, preeclampsia and eclampsia).

\section{Materials and Methods}

It is a descriptive study done at a tertiary care hospital. The study included patients coming to hospital with PIH between the age group 18-40 years. Ethical approval was obtained from the Institutional Ethics Committee. All patients diagnosed to

() The Author(s). 2019 Open Access This article is distributed under the terms of the Creative Commons Attribution 4.0 International License (https://creativecommons. org/licenses/by-nc/4.0/), which permits unrestricted use, distribution, and non-commercial reproduction in any medium, provided you give appropriate credit to the original author(s) and the source, provide a link to the Creative Commons license, and indicate if changes were made. The Creative Commons Public Domain Dedication waiver (http://creativecommons.org/publicdomain/zero/1.0/) applies to the data made available in this article, unless otherwise stated. 
have $\mathrm{PIH}$, i.e., patients having systole $\geq 140 \mathrm{~mm} \mathrm{Hg}$ and diastole $\geq 90 \mathrm{~mm} \mathrm{Hg}$ were included in the study. Patients with multiple pregnancies, women bearing foetuses with chromosomal defects, other obstetric diseases were excluded. Age matched healthy pregnant women were included as controls. Serum Albumin and IMA were analyzed. Serum Albumin measured by bromocresol green method ${ }^{3,4}$ and serum IMA by albumin cobalt-binding test.

\section{The Albumin-Cobalt-binding Test}

Principle: The assay is based on the rationale that ischemia causes changes in human serum albumin (HSA) which can be detected by reduced binding of exogenous cobalt (II). The concentration of serum levels of ischemia modified albumin can be determined by addition of a known amount of cobalt (II) to the serum specimen and measuring the unbound cobalt (II) by colorimetric assay using dithiothreitol (DTT). An inverse relationship thus exists between the level of albumin bound cobalt and the intensity of the colour formation.

Procedure: $200 \mu \mathrm{L}$ of serum is added to $50 \mu \mathrm{L}$ of a solution of $1 \mathrm{gm} / \mathrm{L}$ cobalt chloride. This is mixed and incubated at room temperature for 10 minutes. Dithiothreitol ( $50 \mu \mathrm{L}$ of $1.5 \mathrm{~g} / \mathrm{L}$ solution) is added and mixed. After 2 minutes of incubation, $1.0 \mathrm{~mL}$ of a normal saline is added to the mixture. The absorbance of the assay mixture is read at $470 \mathrm{~nm}$ using Merck semiautoanalyser. The blank is prepared similarly with the exclusion of DTT. The final IMA results are expressed as absorbance units (ABSU).

\section{Statistical Analysis}

Student t-test was used to compare the groups. Mann Whitney $\mathrm{U}$ test was used for statistical analysis. $p<0.05$ is considered significant

\section{ResUlts}

The study was conducted among 80 pregnant women who attended obstetric clinic - 40 pregnant women with PIH and 40 apparently healthy pregnant women. The mean age of the patients was 28.3 years. The mean levels of Ischemia Modified Albumin were much higher in pregnant women with $\mathrm{PIH}(0.52 \pm 0.1 \mathrm{ABSU})$ as compared to pregnant women without PIH $(0.04 \pm 0.03 \mathrm{ABSU})$ and the difference was statistically significant $(p<0.05)$. Figure 1 compares the IMA levels in the two study groups. Out of the 40 cases of PIH, 22 had preeclampsia, six had severe preeclampsia, four had eclampsia and eight were cases of gestational hypertension.

Figure 1 shows box and whisker plot of IMA values in pregnant women with and without PIH. The IMA of the pregnant women with $\mathrm{PIH}$ when compared to without $\mathrm{PIH}$, are much higher at all quartiles; 1st quartile at 0.504 and 3rd quartile at 0.61 along with the median at 0.543 . The whiskers show minimum (0.328) and maximum (0.732) IMA concentrations.

The albumin levels were lower in the pregnant women with $\mathrm{PIH}$ compared to pregnant women without PIH and the difference

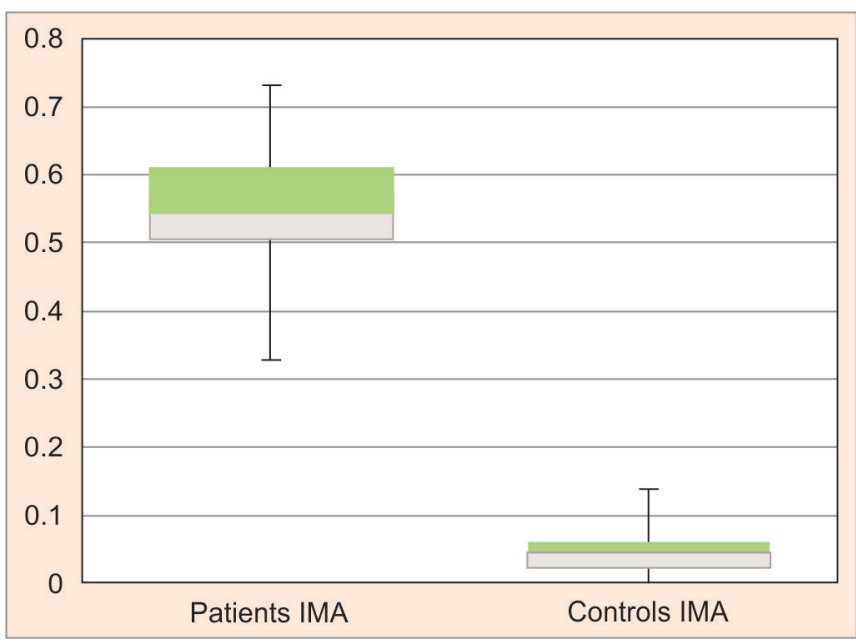

Fig. 1: Box and whisker plot of IMA values of pregnant women with and without PIH

Table 1: Comparison of IMA, albumin and IMA to albumin ratio in pregnant women with and without PIH

\begin{tabular}{lll}
\hline Variables & Patients & Controls \\
\hline IMA (ABSU) & $0.52 \pm 0.1$ & $0.04 \pm 0.03$ \\
Albumin (g/dL) & $2.93 \pm 0.37$ & $3.52 \pm 0.03$ \\
IMA/albumin (ABSU/g/dL) & $0.18 \pm 0.04$ & $0.02 \pm 0.01$ \\
\hline
\end{tabular}

was statistically significant $(p<0.05)$. The ratio of Ischemia Modified Albumin (IMA) to normal serum albumin (IMAR) was higher in the pregnant women with PIH group than the pregnant women without PIH group ( $p<0.05$ ). IMA, albumin and IMA/albumin ratio between the two groups are shown in Table 1.

However, there was no significant difference, when the mean IMA and IMA to albumin ratio levels between the various groups of hypertensive pregnancies i.e. gestational hypertension, preeclampsia, severe preeclampsia and eclampsia were analyzed. Table 2 shows mean albumin, mean IMA levels and mean IMA to albumin ratio in the subgroups of hypertensive pregnancies.

\section{Discussion}

In normal pregnancy, there is an elevated production of free radicals towards the end of pregnancy when compared with non-pregnant women. This rise in oxidant stress is compensated by a gradual increase in total antioxidant capacity (Vitamins C and E) during pregnancy, leading to an oxidative balance which might not happen in hypertensive pregnancy. ${ }^{5}$

In normal pregnancies, there is remodeling at the placental vascular bed, where cytotrophoblast invades the maternal spiral arteries and makes them lose their smooth muscle to become sinusoids. These vessels have greater diameter and lower resistance. ${ }^{5}$ However, in pre-eclampsia; there is defective

Table 2: Comparison of mean albumin, mean IMA levels and mean IMA to albumin ratio in the various hypertensive pregnancies

\begin{tabular}{lllll}
\hline Variables & $\begin{array}{l}\text { Gestational hypertension } \\
(n=8)\end{array}$ & $\begin{array}{l}\text { Pre-eclampsia } \\
(n=22)\end{array}$ & $\begin{array}{l}\text { Severe pre-eclampsia } \\
(n=6)\end{array}$ & $\begin{array}{l}\text { Eclampsia } \\
(n=4)\end{array}$ \\
\hline IMA (ABSU) & $0.54 \pm 0.1$ & $0.51 \pm 0.1$ & $0.55 \pm 0.07$ & $0.54 \pm 0.07$ \\
Albumin (g/dL) & $2.92 \pm 0.24$ & $2.9 \pm 0.39$ & $3.05 \pm 0.39$ & $3.1 \pm 0.39$ \\
IMA/albumin (ABSU/g/dL) & $0.19 \pm 0.03$ & $0.18 \pm 0.05$ & $0.18 \pm 0.04$ & $0.17 \pm 0.03$ \\
\hline
\end{tabular}


trophoblastic invasion and impaired remodelling of the uterine spiral arteries. The arteries might retain their smooth muscle and remain under vasomotor control. The focal hypoxia initiates endothelial dysfunction, reperfusion and oxidative damage. ${ }^{6}$

Our study showed significant increase in the levels of IMA and IMA to albumin ratio in Pregnancy Induced Hypertension thus supporting IMA as a marker of oxidant stress in this condition. This is similar to the study of Bahinipati JT et al who compared 45 pre-eclamptic patients with 31 pregnant healthy controls in which, they found that IMA and MDA (Malondialdeyde, an oxidative stress marker) levels were significantly elevated in the preeclamptic group as compared to the controls' and a significant correlation was found between the two markers. ${ }^{1}$ Similar results were seen in various other studies. $^{7-9}$

However in a study by Rijn $\mathrm{V}$ et al where they compared 12 preeclampsia patients, 12 pregnant controls and 12 nonpregnant controls, they found that IMA level was elevated in pregnant and nonpregnant controls and that there was no significant difference in the IMA levels between the preeclampsia patients and pregnant controls. Such disparity in results among various studies could be due to differences in the severity of preeclampsia among different patients. ${ }^{6}$

In our study there was no correlation of the IMA levels and IMAR with the severity of PIH. It does not differentiate between gestational hypertension, preeclampsia and eclampsia. However the analysis by Chamy VM et al shows that antioxidant enzyme activity (SOD, GPx, ABTS) was significantly decreased, while lipoperoxidation (MDA) was increased in preeclamptic groups compared to normal pregnant women $(p<0.01)$ and statistically significant difference was found between mild and severe preeclamptic groups $(p<0.01)$, suggesting the rationale that oxidant stress markers correlate with the severity of the disease. ${ }^{10}$

\section{Ethical Considerations}

All procedures performed in studies involving human participants were in accordance with the ethical standards of the institutional and/or national research committee and with the 1964 Helsinki declaration and its later amendments or comparable ethical standards.

\section{References}

1. Bahinipati JT, Mohapatra CP, Pradhan T. Role of maternal serumischemia modified albumin as a biochemical marker inpreeclampsia. Biomed Res-India 2014;25:11-14.

2. $\mathrm{Wu} A \mathrm{AH}$. The ischemia-modified albumin biomarker for myocardialischemia.MLO Med Lab Obs 2003;35(6):36-8,40.

3. Gustafsson JE. Improved specificity of serum albumin determination and estimation of "acute phase reactants" by use ofthe bromocresol green reaction. Clinical Chemistry 1976;22(5):616-22.

4. Ueno T, Hirayama S, Ito M, Nishioka E, Fukushima $Y$, Satoh T et al. Albumin concentration determined by the modified bromocresol purple method is superior to that by the bromocresol green method for assessing nutritional status in malnourished patients with inflammation. Ann ClinBiochem 2013;50(6):576-84.

5. Negi R, Pande D, Karki K, Khanna RS, Khanna HD. Oxidative Stressand Preeclampsia. als. 2011;1(1):20-23.

6. van Rijn BB, Franx A, Sikkema JM, van Rijn HJM, Bruinse HW, Voorbij HAM. Ischemia Modified Albumin in Normal Pregnancy and Preeclampsia. Hypertension in pregnancy 2008;27:159-67.

7. Dayanand CD, Bambrana V, Sivaraj N, Inala MSR. Is ischemia Modified Albumin a Marker in Preeclampsia? A Case Control Study in Kolar Population-a South West of India. Am. J. Pharm Health Res 2015;3(6):84-90.

8. Vyakaranam S, Bhongir AV, Patlolla D, Chintapally R. Maternal serum ischemia modified albumin as a marker for hypertensive disorders of pregnancy: a pilot study. Int J Reprod Contracept Obstet Gynecol. 2015;4:611-6.

9. D'souza JM, Pai VR, Harish S, Shriyan C, D'souza N. IMA and IMAR in serum and saliva of preeclampsia - a preliminary study. Hypertens Pregnancy. 2014;33(4):440-8

10. Chamy VM, Lepe J, Catalán A, Retamal D, Escobar JA, Madrid EM. Oxidative stress is closely related to clinical severity of preeclampsia. Biol Res 2006;39(2):229-36.

11. Bowen RS, Moodley J, Dutton MF, Theron AJ. Oxidative stress inpreeclampsia. Acta obstet gynaecol scand.2001;80[8]:719-25.

12. Rossi A, Bortolotti N, Vescovo S, Romanello I, Forzano L, Londero AP et al. Ischemia modified albumin in pregnancy. Eur J Obstet Gynecol Reprod Biol. 2013;170[2]:348-51. 